\title{
Myelinated fibres in human paravertebral sympathetic chain: white rami communicantes in alcoholic and diabetic patients
}

\author{
OTTO APPENZELLER AND GARY OGIN \\ From the Department of Neurology, The University of New Mexico School of Medicine, \\ Albuquerque, New Mexico, U.S.A.
}

SYNOPSIS White rami communicantes were studied quantitatively in patients with chronic alcoholism or diabetes mellitus. The fascicular area of interganglionic segments of the paravertebral sympathetic chain showed less variation than that previously reported for controls. Fibre densities were higher in the patients than in controls of similar age and the percentage of small fibres in alcoholics and diabetics is larger than in controls. Only $17 \%$ of fibres were larger than $5 \mu \mathrm{m}$ in diameter in the patients, whereas, in controls, $33 \%$ of fibres were larger than $5 \mu \mathrm{m}$ in diameter. No correlation between internodal lengths and fibre diameter was found in the patients who showed uniformly short internodes averaging only about haif of internodal distances found in control subjects. The uniformly short internodes are attributed to complete degeneration followed by partial regeneration and are compatible with either Wallerian degeneration or a 'dying back' phenomenon. The short internodal lengths should be reflected in slowed conduction velocities in white rami communicantes and could account for abnormalities in baroreflex activity, sweating, and in visceral dysfunction commonly seen in patients with chronic alcoholism or diabetes.

The importance of autonomic dysfunction in patients with chronic alcoholism and diabetes mellitus is widely recognized clinically but the morphological correlates of these disturbances have rarely been sought and the findings have often been controversial. Some have suggested that, in both alcoholism and diabetes, the metabolic disturbances directly affect peripheral nerves. This impression appears to be supported by clinical observations that reflex and sensory abnormalities can change with improvement in the metabolic state of both alcoholics and diabetics. In diabetic neuropathy objective evidence of changes in motor conduction velocities paralleling acute alterations in the metabolic state have also been reported (Gregersen, 1968). The metabolic theory implies impairment or improvement of peripheral nerve function due to a direct effect on Schwann cell metabolism. Others have maintained that, at least in diabetic patients, the pathological changes in blood vessels of peripheral autonomic and somatic nerves are responsible for functional disturbances (Woltman and Wilder, 1929; Fagerberg, 1959). This view is supported by the demonstration of progressive deterioration in function which seems to parallel the duration of the disorder and the general correlation of disease in other organs which is attributed to angiopathy.

Pathological changes in the autonomic peripheral nervous system in alcoholic and diabetic neuropathies include giant sympathetic neurones (Appenzeller and Richardson, 1966), other degenerative changes in the paravertebral sympathetic chain, and neuromata of the post-ganglionic autonomic fibres around blood vessels and other viscera. It was even suggested that socalled diabetic angiopathy is a consequence of primary damage to the vasomotor nerves leading to partial or complete denervation of blood vessels with subsequent denervation supersensitivity (Budzilovich, 1970).

Autonomic function has been shown to deteriorate with advancing years (Appenzeller 
and Descarries, 1964; Gross, 1970). The morphological correlates of this functional deterioration with age have now been partially defined (Appenzeller and Ogin, 1973). A reduction in internodal lengths of white rami communicantes in old age has been found. Wallerian degeneration and segmental demyelination also occur and regeneration of white rami communicantes does not appear to keep pace with successive degenerative events in older subjects. In the present study quantitative measurements were made on white rami communicantes from patients with alcoholism or diabetes without clinically recorded impairment of peripheral nerve or autonomic function. The results were compared with measurements obtained from control subjects of similar age (Appenzeller and Ogin, 1973).

\section{METHODS}

Preganglionic myelinated fibres from the intermediolateral cell column enter the anterior roots between $T_{1}$ and $L_{2}$ and some leave the roots as white rami communicantes. They reach the sympathetic paravertebral chain and course up and down the chain or through it before synapsing on neurones and on viscera or within the ganglia. These are the myelinated fibres within the paravertebral sympathetic chain which were examined in this and our previous study (Appenzeller and Ogin, 1973). The paravertebral sympathetic chain was taken at necropsy from patients dying from the effects or complications of chronic alcoholism or diabetes. Review of hospital records during many previous admissions showed no clinical evidence of peripheral or autonomic nerve dysfunction. The age, sex, diagnosis, and causes of death of the patients are shown in the Table.

A specimen measuring 5 to $7 \mathrm{~cm}$ in length and including the third to the fifth thoracic ganglia was stretched over a piece of cardboard and air dried for a few minutes before immersion in $10 \%$ formolsaline. Post-fixation was carried out in $1 \%$ osmium tetroxide for 24 hours. An interganglionic segment of the paravertebral sympathetic chain was dissected for examination and the tissue was embedded in paraffin and sectioned at $4 \mu \mathrm{m}$. The sections were dehydrated, cleared, and mounted in Canada balsam; cross-sections were photographed at a magnification of $\times 10.5$ for an overview, photographs of representative areas of the cross-section were also taken at a magnification of $\times 258$. Fibre diameter spectra were made after projecting the negatives onto an aluminium screen through a film projector at a
TABLE

CLINICAL DETAILS OF PATIENTS

\begin{tabular}{|c|c|c|c|}
\hline Case & $\begin{array}{l}\text { Age }(y r) \\
\quad \text { sex }\end{array}$ & Diagnosis & Necropsy findings \\
\hline 1 & $30 \mathrm{M}$ & Alcoholism & Acute liver failure \\
\hline 2 & $31 \mathrm{M}$ & Alcoholism & $\begin{array}{l}\text { Nutritional cirrhosis, bleeding } \\
\text { oesophageal varices, massive } \\
\text { mediastinal haemorrhage }\end{array}$ \\
\hline 3 & $65 \mathrm{M}$ & Alcoholism & Pneumonia \\
\hline 4 & $72 \mathrm{M}$ & Alcoholism & $\begin{array}{l}\text { Bronchopneumonia, chronic liver } \\
\text { failure, cirrhosis, septicaemia }\end{array}$ \\
\hline 5 & $59 \mathrm{~F}$ & $\begin{array}{l}\text { Diabetes } \\
\text { mellitus }\end{array}$ & $\begin{array}{l}\text { Myocardial infarction, hyperten- } \\
\text { sive cardiovascular disease }\end{array}$ \\
\hline 6 & $61 \mathrm{~F}$ & $\begin{array}{l}\text { Diabetes } \\
\text { mellitus }\end{array}$ & Nephrotic syndrome, pneumonia \\
\hline 7 & $64 \mathrm{~F}$ & $\begin{array}{l}\text { Diabetes } \\
\text { mellitus }\end{array}$ & $\begin{array}{l}\text { Cerebral vascular accident, myo- } \\
\text { cardial infarction }\end{array}$ \\
\hline 8 & $68 \mathrm{M}$ & $\begin{array}{l}\text { Diabetes } \\
\text { mellitus }\end{array}$ & Cerebral haemorrhage, pneumonia \\
\hline 9 & $70 \mathrm{~F}$ & $\begin{array}{l}\text { Diabetes } \\
\text { mellitus }\end{array}$ & $\begin{array}{l}\text { Congestive heart failure, dissemin- } \\
\text { ated intravascular coagulopathy, } \\
\text { ileus }\end{array}$ \\
\hline
\end{tabular}

final magnification of $\times 8,920$. A planimeter was used for measurement of fascicular area of the pros jected image at a final magnification of $\times 121$.

Internodal length was measured on single fibres teased from interganglionic tissue. The formalio fixed samples were post-osmicated in $1 \%$ osmium tetroxide solution for 24 hours. The tissue was the washed in several changes of distilled water, buffere at $\mathrm{pH} 1.5$ to 2 , and stretched lengthwise into fine pieces. Samples were incubated in buffered $0.5 \%$ pepsin solution at $37^{\circ} \mathrm{C}$ for two to three weeks with solution changes at 24 hour intervals. After some days of incubation the digestion of the tissue was aided by gentle teasing of bundles under a dissecting

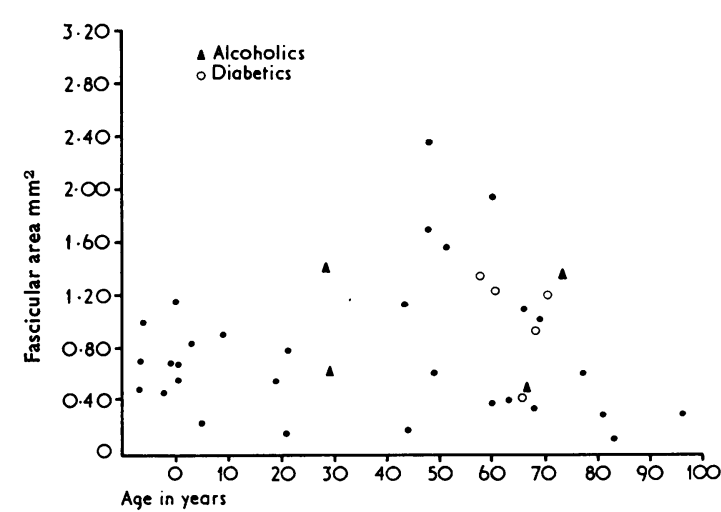

FIG. 1. Fascicular area plotted against age. Controls: •. 
microscope to remove the digested areas and facilities penetration of the enzyme. Enzyme activity was allowed to continue until fibres separated readily. The tissue was then washed in distilled water and soaked in $7 \%$ glycerin ethanol solution for 24 hours. Single fibres were separated in glycerin and transferred to glass slides for mounting in Canada balsam. Measurements of internodal length were made at a magnification of $\times 430$ and of single fibre diameters at a magnification of $\times 880$. Five measurements of diameter were made along each internode the mean of these readings being taken as the diameter of the internode. Measurements of internodal length by this method have previously been checked (Appenzeller and Ogin, 1973) and found to be similar to those obtained from preparations made by the methods of Vizoso and Young (1948) and by Thomas and Young (1949).

\section{RESULTS}

In alcoholic and in diabetic patients the arrangement of myelinated fibres in the paravertebral sympathetic chain is similar to that found in controls. A predominantly marginal distribution of myelinated fibres with occasional islands of fibres interspersed throughout the rest of the tissue was found. Small or large fibres predominated in some cross-sections of interganglionic segments; in other cross-sections a mixture of both large and small myelinated fibres were found. Considerable variation in

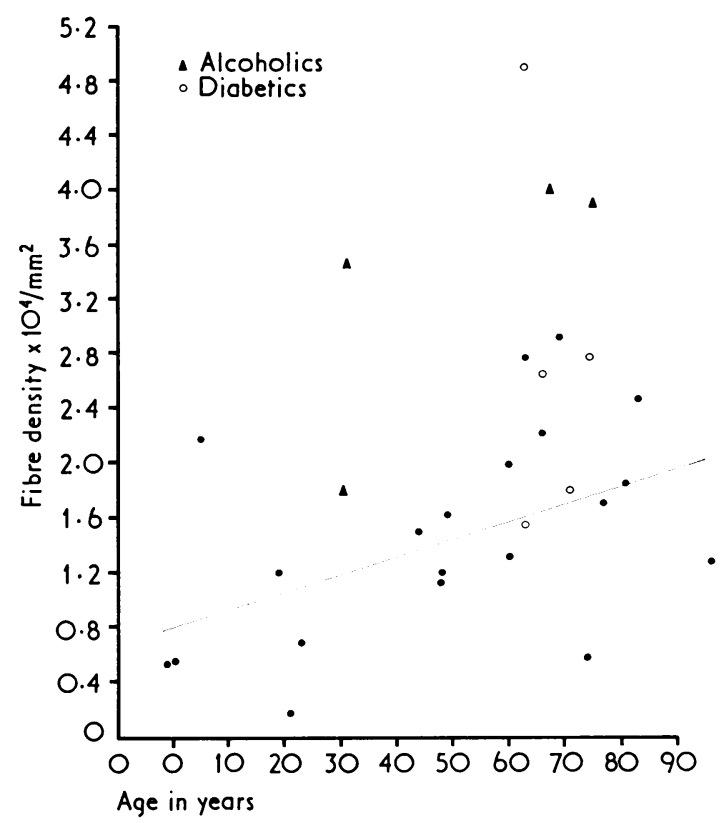

FIG. 2. Fibre density plotted against age. Controls: •.

fascicular area was found in patients with alcoholism and diabetes though this variation was less marked than that previously reported in controls (Fig. 1). Values ranged from $0.68 \mathrm{~mm}^{2}$ to $1.41 \mathrm{~mm}^{2}$; these measurements fell within the
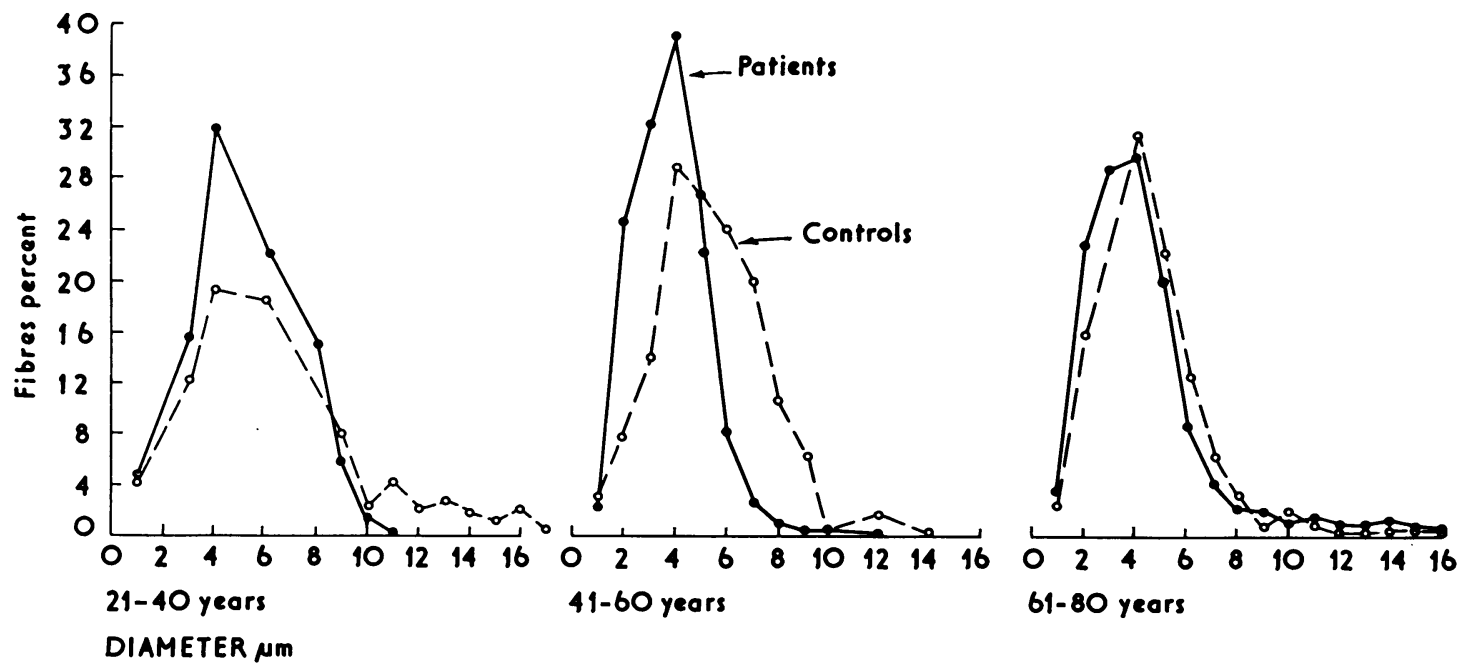

FIG. 3. Average fibre size spectra. Most patients had more small fibres than controls. 


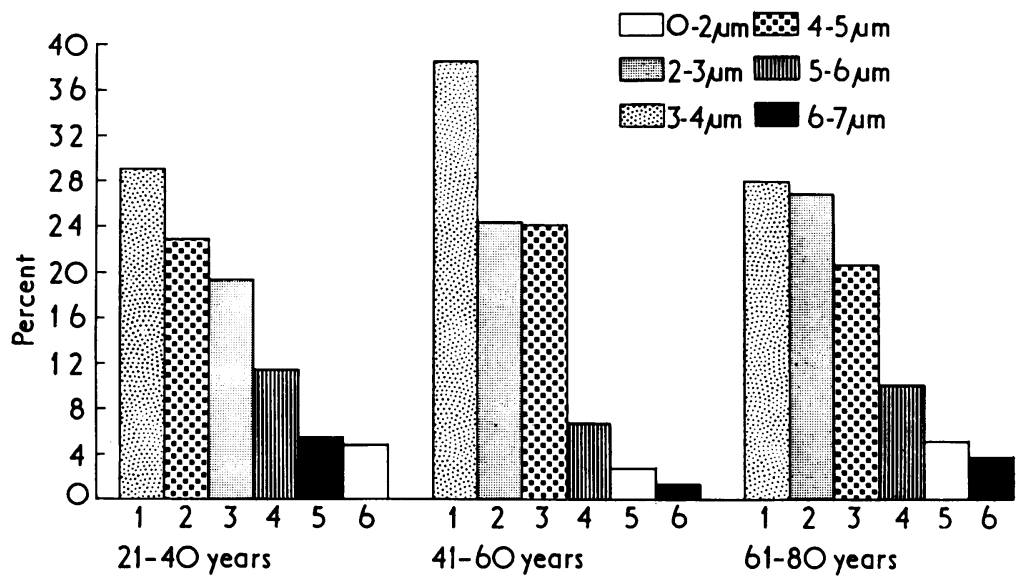

FIG. 4. Rank order of six most frequently encountered fibre diameters.

normal range. There was no correlation between fascicular area and age of the patients.

Fibre density expressed as the number of myelinated fibres per square millimetre of intraperineural area is shown in Fig. 2. Densities ranged from 12,000 to 50,000 myelinated fibres per $\mathrm{mm}^{2}$. Patients had generally higher densities than normals for age. Average fibre size spectra for age are shown in Fig. 3. The percentage of small fibres is larger in alcoholics and diabetics than in controls; however, patients aged 61 years or older showed a fibre size spectrum similar to controls. The rank order of fibre diameters is illustrated in Fig. 4. The percentage of fibres $5 \mu \mathrm{m}$ or less in diameter was larger in patients below 60 years. Fibres greater than $5 \mu \mathrm{m}$ in diameter averaged only $17 \%$ in the patients, whereas in controls $33 \%$ of fibres were larger than $5 \mu \mathrm{m}$ in diameter. The variability of fibre sizes in interganglionic segments is given by the ratio of mean to median shown in Fig. 5. The larger the ratio the greater the variability of fibre $\overrightarrow{0}$ size. The closer clustering near unity suggests. that in patients the fibre sizes were less variab度 than in controls.

A correlation between internodal lengths and fibre diameter in control white rami commun cantes was previously demonstrated for all a groups (Appenzeller and Ogin, 1973). By cout trast none of the patients showed the expected increase in internodal lengths with increasing $\stackrel{\oplus}{\perp}$ fibre diameter and statistical analysis showed no correlation of these measurements in any patient (Fig. 6). Uniform short internodes were generally found. Regenerating fibres after Wallerian degeneration have uniformly short internodes. $\stackrel{\mathbb{D}}{\triangle}$ Fibres affected by segmental demyelination and $\overrightarrow{\vec{A}}$ remyelination have internodes of normal and

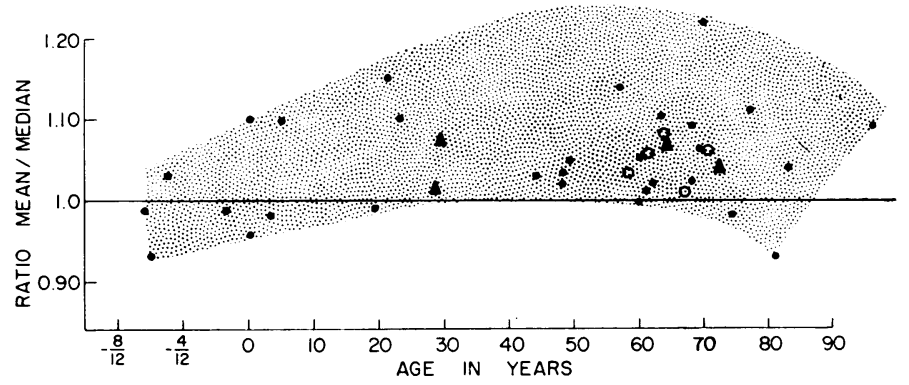

FIG. 5. Ratio of mean to median fibre diameters. Patients are superimposed on a background of hypothetical range of normal and control values $(\bullet)$.

$\triangle$ ALCOHOLICS O DIABETICS 


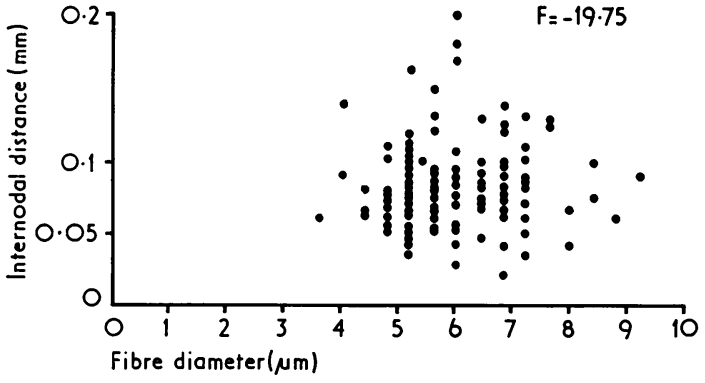

FIG. 6. Example of internodal distance plotted against fibre diameter (case 2). There was no statistical relationship between internodal distance and fibre diameter.

reduced lengths (Fullerton et al., 1965; Thomas and Lascelles, 1965). The uniformly short internodes found with few exceptions in patients suggest that most fibres had undergone Wallerian degeneration and partial regeneration (Fig. 7).

\section{DISCUSSION}

Biometric data for myelinated fibres in peripheral nerves suggest that sheath thickness and fibre calibre are in constant relationship. Internodal lengths in peripheral myelinated fibres are also directly related to fibre size. This relationship is preserved in white rami communicantes of normal subjects but internodal distance is only about one-third the length of internodes in the sural nerve for any given fibre size (Appenzeller and Ogin, 1973).

In the present study of chronic alcoholics and diabetics the morphological appearance of myelinated fibres on cross-sections of the interganglionic paravertebral sympathetic chain was indistinguishable from that of controls, though higher fibre densities were found in the patients. Fibre densities may be affected by changes in fascicular area or by the number of fibres. Since fascicular area did not differ significantly from controls of similar age, we must conclude that the higher densities were due to an increase in the number of fibres. Because of larger numbers of smaller calibre fibres in patients, the higher densities are attributed to a disproportionate increase in the number of fibres less than $5 \mu \mathrm{m}$ in diameter. This suggests that degeneration and regeneration with axonal sprouting occurs in chronic alcoholism and diabetes mellitus. The finding that the fibre size spectrum in alcoholics and diabetics older than 61 years of age is similar to controls might be due to an exhaustion of regenerative mechanisms and cessation of axonal

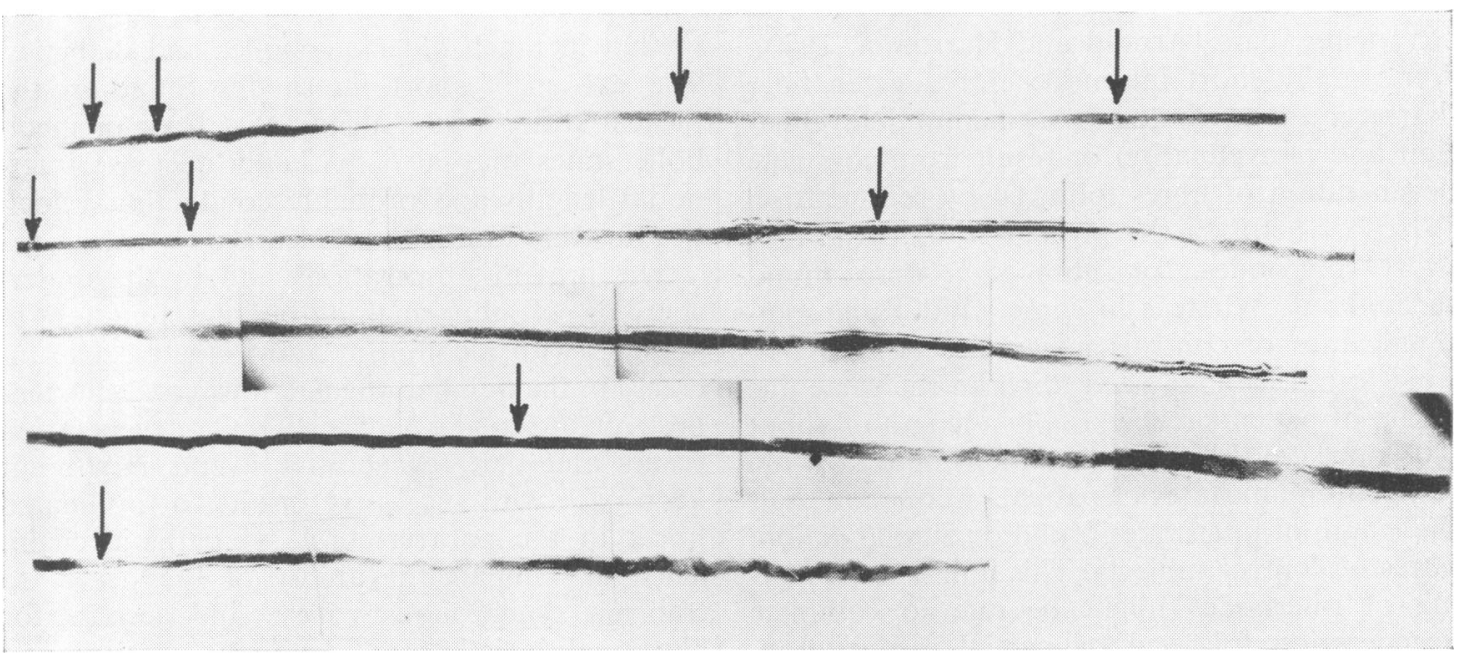

FIG. 7. Case 2. Single teased white ramus communicans. Consecutive photographs (left to right and top to bottom) showing nine nodes of Ranvier (arrows) at irregular intervals. $\times 500$. 
sprouting in myelinated fibres exposed to toxic or metabolic disturbances for a long time. This interpretation is supported by the finding that only about half the number of fibres larger than $5 \mu \mathrm{m}$ were present in the patients when compared with controls of all ages. Moreover, the decreased variability in fibre size in patients is suggestive of a more uniform population of small fibres-presumably as a result of regenerative efforts after repeated injury.

Dissection of single white rami communicantes has not been practised until recently (Appenzeller and Ogin, 1973). However, the technique was first perfected by Gombault in 1880 on peripheral nerves and it is particularly useful for the demonstration of segmental demyelination. By this method segmental demyelination was shown to occur in peripheral nerves of patients with diabetes (Thomas and Lascelles, 1966), diphtheria (Cavanagh and Jacobs, 1964), peroneal muscular atrophy (Gutrecht and Dyck, 1966), and chronic uraemia (Appenzeller et al., 1971). Changes in single white rami communicantes in controls of various ages have been reported (Appenzeller and Ogin, 1973). Segmental demyelination was found in older subjects and successive remyelination was demonstrated by the presence of internodes of different lengths on many fibres (Appenzeller and Ogin, 1973). In sural nerves, irregularities of internodal lengths in normal subjects have also been reported and these become more frequent with advancing years (Arnold and Harriman, 1970). Abnormally short internodes for a given fibre diameter are attributed to segmental demyelination and remyelination or result from complete degeneration of fibres followed by regeneration (Vizoso, 1950). In the present study, extremely short internodes for fibre size were found throughout. Whereas in some white rami communicantes of controls internodes of $0.15 \mathrm{~mm}$ were found, similar sized fibres in the same age group of patients reached only a length of about $0.08 \mathrm{~mm}$. On the whole, the internodes in white rami communicantes of patients were about half the length of internodes found on similar calibre fibres of control subjects. This uniform shortening of internodes might be due to complete degeneration followed by partial regeneration, but widespread segmental demyelination and remyelination, though usually producing inter- nodes of different lengths on the same fibre, may rarely also lead to an uniform shortening of internodes. Occasionally fibres with internodes of varying lengths were present but these were not frequent, most fibres showing uniformly short internodes for fibre size. The present observations are consistent also with a 'dying back' phenomenon. This could result from a direct effect of toxic or metabolic factors on the intermediolateral cell column in the spinal cord of the patients.

The short internodal length should be reflected in slow conduction velocities. Though conduction velocities in human myelinated fibres in the paravertebral sympathetic chain have not been reported, velocities of 1.2 metres per second have been found in the cervical sympathetic chain of the rat (Sacchi and Perri, 1969). Using data obtained in our previous study for internodal $\omega_{y}$ length in control subjects, conduction velocities in human paravertebral sympathetic chair should be about one-third that of normal perf pheral nerves and velocities should decrease gradually with advancing years because of the increase in the frequency of irregularities internodal distances. Damage to white rami h\& previously been shown to result in extreme short internodes for age. Thus, uniformly shợ internodes were encountered in a patient aged $\overrightarrow{3} \overrightarrow{0}$ years who received $x$-radiation to the region of the spinal cord (Appenzeller and Ogin, 1973). The internodal length in this patient was similar to that in much older alcoholics and diabetics. The extremely short internodes found in the $\frac{0}{\mathbb{D}}$ present study would suggest that toxic or metabolic states may also markedly decrease inter-을 nodal lengths and probably conduction velocities in white rami communicantes.

The present observations add to the understanding of abnormal autonomic function in patients with alcoholism and diabetes. The in-: crease in the number of small fibres and shortening of internodes suggest that degeneration recurs and that regenerative events might not keep pace with successive insults to myelinated음 fibres in the paravertebral sympathetic chain. $D$ This may impair the ability of the nerves to transmit synchronous volleys and account for $N$ abnormalities in baroreflex activity, sweating, and ${ }_{N}$ visceral dysfunction commonly seen in patients with chronic alcoholism and diabetes. 


\section{REFERENCES}

Appenzeller, O., and Descarries, L. (1964). Circulatory reflexes in patients with cerebrovascular disease. New England Journal of Medicine, 271, 820-823.

Appenzeller, O., Kornfeld, M., and MacGee, J. (1971). Neuropathy in chronic renal disease. A microscopic, ultrastructural, and biochemical study of sural nerve biopsies. Archives of Neurology, 24, 449-461.

Appenzeller, O., and Ogin, G. (1973). Myelinated fibres in the human paravertebral sympathetic chain; quantitative studies on white rami communicantes. Journal of Neurology, Neurosurgery, and Psychiatry, 36, 777-785.

Appenzeller, O., and Richardson, E. P., Jr (1966). The sympathetic chain in patients with diabetic and alcoholic polyneuropathy. Neurology (Minneap.), 16, 1205-1209.

Arnold, N., and Harriman, D. G. F. (1970). The incidence of abnormality in control human peripheral nerves studied by single axon dissection. Journal of Neurology, Neurosurgery, and Psychiatry, 33, 55-61.

Budzilovich, G. N. (1970). Diabetic neuropathy complex. Virchows Archiv: Abteilung A. Pathologische Anatomie, 350, 105-122.

Cavanagh, J. B., and Jacobs, J. M. (1964). Some quantitative aspects of diphtheritic neuropathy. British Journal of Experimental Pathology, 45, 309-322.

Fagerberg, S. E. (1959). Diabetic neuropathy. A clinical and histological study on the significance of vascular affections. Acta Medica Scandinavica, 164, Suppl. 345.

Fullerton, P. M., Gilliatt, R. W., Lascelles, R. G., and Morgan-Hughes, J. A. (1965). The relation between fibre diameter and internodal length in chronic neuropathy. Journal of Physiology, 178, 26-28P.

Gombault, A. (1880). Contribution à l'étude anatomique de la névrite parenchymateuse subaiguë et chronique.Névrite segmentaire péri-axile. Archives de Neurologie (Paris), 1, 11-38.

Gregersen, G. (1968). Variations in motor conduction velocity produced by acute changes of the metabolic state in diabetic patients. Diabetologia, 4, 273-277.

Gross, M. (1970). The effect of posture on subjects with cerebrovascular disease. Quarterly Journal of Medicine, 39, 485-491.

Gutrecht, J. A., and Dyck, P. J. (1966). Segmental demyelinization in peroneal muscular atrophy: nerve fibers teased from sural nerve biopsy specimens. Mayo Clinical Proceedings, 41, 775-777.

Sacchi, O., and Perri, V. (1969). Effetti della piritiamina e dell ossitiamina sull ampiezza del potenziale d'azione e la velocita di conduzione delle fibre del tronco simpatico cervicale del ratto. Bollettino della Società Italiana di Biologia Sperimentale, 45, 1597-1601.

Thomas, P. K., and Lascelles, R. G. (1965). Schwann-cell abnormalities in diabetic neuropathy. Lancet, 1, 1355-1357.

Thomas, P. K., and Lascelles, R. G. (1966). The pathology of diabetic neuropathy. Quarterly Journal of Medicine, 35 , 489-509.

Thomas, P. K., and Young, J. Z. (1949). Internode lengths in the nerves of fishes. Journal of Anatomy, 83, 336-350.

Vizoso, A. D. (1950). The relationship between internodal length and growth in human nerves. Journal of Anatomy, 84, 342-353.

Vizoso, A. D., and Young, J. Z. (1948). Internode length and fibre diameter in developing and regenerating nerves. Journal of Anatomy, 82, 110-134.

Woltman, H. W., and Wilder, R. M. (1929). Diabetes mellitus. Pathologic changes in the spinal cord and peripheral nerves. Archives of Internal Medicine, 44, 576-603. 